\title{
The Impact of Modeling on the Architectural Project Formation (Architecture Students in Iraq as a Case Study)
}

\author{
Saad Mohsin Hmoud ${ }^{1}$, Noor Mukhlis Ibrahim ${ }^{2, *}$ \\ ${ }^{1}$ Al-Nahrain University/ College of Engineering/ Department of architecture, Iraq \\ ${ }^{2}$ University of Technology/College of Architecture, Iraq
}

\begin{abstract}
This research aims to find modeling strategies that students of architectural department used to producing and formation their architectural projects and study the impact of modeling types (handmade model, digital model, parametric model, etc.) on the relationship between architect conception and client Understanding. Research methodology: At the first section, the study examines the modeling concept, messages, Communication and the significance of model and modeling strategies. In the second section of the study discussed the modeling formation, Form production methods, modeling mechanisms types and what's modeling methods that Adoption from the students and how that Consistent in the expression of the they architecture concepts. The research presented the modeling and design methodology and that Effectiveness on development students Skills and abilities in project presentation and understanding the simple forms and the complicated forms. In the third section of the study, Research analyze different student's projects and find the strategies of modeling according to the equipment available to them. The Multiple modeling is introduced as a key modeling strategy in architecture project formation and definition the impact of differentiation modeling type on understanding the architecture design and presentation methods.
\end{abstract}

Keywords: design; digital-model; handmade-model; modeling-strategies; parametric-model 